\title{
FENOLOGI DAUN Dicksonia blumei (Kunze) Moore DI KEBUN RAYA "EKA KARYA" BALI, INDONESIA
}

\author{
(Leaf phenology of Dicksonia blumei (Kunze) Moore at "Eka Karya” Bali Botanic \\ Garden, Indonesia)
}

Siti Fatimah Hanum

Balai Konservasi Tumbuhan Kebun Raya "Eka Karya "Bali-LIPI

Candikuning, Baturiti, Tabanan, Bali, Indonesia 82191

E-mail: sitifatimahhanum2004@yahoo.com

Tanggal diterima: 4 April 2018; Tanggal direvisi: 28 Januari 2019; Tanggal disetujui; 13 Mei 2019

\begin{abstract}
Dicksonia blumei (Kunze) Moore is one type of tree ferns that can be utilized as medicinal and ornamental plant. However, literature on phenology research of this species, is very limited even to date. The purpose of this research is to understand the phenology phase of $\underline{D}$. blumei and to analyze the correlation of each phenology phase to climate factor, particularly temperature and rainfall. This information is expected to support $\underline{D}$. blumei's reintroduction activities. The phenology of $\underline{D}$. blumei in Eka Karya Bali Botanical Garden was observed from May 2015 to May 2016 using 30 plant samples. Several samples produced sterile and fertile leaves during observation. Phenological phases include frond emergence, leaf development, leaf maturation (characterized by spore), leaf senescence and mature spore formation until spore release. The number of developed leaves was less than the number emerged frond, while the number of whitered leaves was less than the number of matured leaves. The average number of days needed from frond to withered phase was $254.31 \pm$ 6.8 days. Leaf development phase was negatively correlated with temperature, while leaf senescence phase was positively correlated with rainfall. Fertility and leaf production were not correlated with climate factors or seasonal variations. These results show that phenological rhythms of $\underline{D}$. blumei were not influenced by climate variations.
\end{abstract}

Keywords: Dicksonia blumei, phenology, rainfall, temperature

\begin{abstract}
ABSTRAK

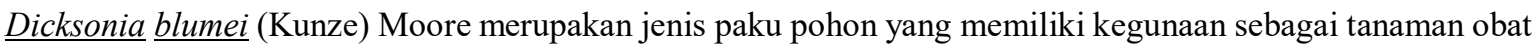
dan hias. Namun demikian, sampai saat ini belum banyak literatur yang membahas fenologi jenis paku tersebut. Penelitian ini bertujuan untuk mengetahui fase fenologi D. blumei dan menganalisa hubungan setiap fase fenologi dengan faktor iklim (suhu dan curah hujan). Informasi ini diharapkan dapat mendukung kegiatan reintroduksi D. blumei. Fenologi D. blumei diamati selama satu tahun (Mei 2015 sampai Mei 2016) menggunakan 30 sampel tanaman di Kebun Raya "Eka Karya”Bali. Beberapa sampel menghasilkan daun steril dan fertil selama pengamatan. Fase fenologi meliputi munculnya daun, perkembangan daun, daun dewasa yang ditandai adanya spora, daun layu dan terbentuknya spora matang hingga lepasnya spora. Jumlah daun yang berkembang lebih sedikit dibanding jumlah daun yang muncul, dan jumlah daun yang layu lebih sedikit dibandingkan dengan jumlah daun yang sudah dewasa. Total jumlah hari yang dibutuhkan dari fase daun muncul hingga fase layu adalah $254,31 \pm 6,8$. Fase perkembangan daun berkorelasi negatif dengan suhu, sementara fase daun layu berkorelasi positif dengan curah hujan. Namun, produksi daun dan pembentukan spora tidak dipengaruhi oleh faktor iklim atau variasi musiman. Hal ini memperlihatkan bahwa fenologi D. blumei tidak dipengaruhi oleh variasi musiman.
\end{abstract}

Kata kunci: Fenologi, Dicksonia blumei, suhu, curah hujan 


\section{PENDAHULUAN}

Fenologi merupakan studi terkait perioditas (waktu) proses biologi yang dipengaruhi oleh faktor intrinsik atau ekstrinsik atau kombinasi dari kedua faktor tersebut (Mehltreter, 2008). Beberapa penelitian memperlihatkan bahwa fenologi paku bersifat musiman yang berkaitan dengan suhu, presipitasi dan curah hujan (Chiu, 2013; Lee, Chiou, \& Huang, 2009a). Penelitian terkait fenologi paku dan pengaruh lingkungan terhadap fenologi merupakan faktor yang penting untuk memahami biologi dan ekologi spesies dalam rangka mengembangkan program untuk memelihara dan mengembalikan populasi spesies untuk tujuan konservasi (Noland, Norman, Peterson, \& Richardson, 2017). Meski demikian sebagian besar studi fenologi dilakukan pada tanaman berbunga dibandingkan pada paku, yang merupakan tumbuhan bawah dominan di hutan (Lee, Lin, \& Chiou, 2009).

Tanaman memiliki kemampuan untuk mengontrol waktu keluarnya daun dan ketahanan daun dengan cara memaksimalkan hasil fotosintesa sebagai respon terhadap ketersediaan kondisi cahaya matahari dan meminimalkan kerusakan yang disebabkan oleh kondisi beku, kekeringan dan herbivora (Quintanilla \& Pías, 2018) Daun paku memiliki fungsi penting sebagai pengubah energi, sehingga informasi terkait jumlah, ukuran dan karakteristik fungsional daun seperti masa hidup penting bagi pertumbuhan dan bertahannya tanaman (Mehltreter \& Sharpe, 2013). Fase perkembangan daun dan pembentukan spora merupakan fase penting yang diamati selama fenologi paku (Lee, Huang, \& Chiou, 2018)

Fenologi paku baru mendokumentasikan sebanyak 225 species (2\%) dari total perkiraaan paku saat ini yang berjumlah sekitar 10.578 di seluruh dunia. Sebagian besar fenologi paku berasal dari belahan bumi bagian utara terutama daerah temperate, dan hanya sedikit yang berasal dari daerah tropis. Pendokumentasian paku pohon sendiri hanya 32 spesies (Lee et al., 2018). Paku pohon ditemukan di hutan basah di seluruh dunia dari hutan tropis hingga hutan temperate yang dingin. Paku pohon sering memainkan peran penting secara fisik dan ekologi. Batang paku pohon menjadi rumah bagi paku epifit dan lumut (Blair, Blanchard, Banks, \& Lindenmayer, 2017). Meski paku pohon merupakan vegetasi hutan tropis yang menyolok dan menarik perhatian dari pakar ekologi selama kurun waktu sepuluh tahun, tetapi hanya sedikit informasi yang diketahui terkait fenologi daunnya dan faktor lingkungan yang mempengaruhi munculnya daun, daun layu dan kesuburan (Mehltreter \& García-franco, 2008).

Paku kidang (D. Blumei) merupakan salah satu jenis paku pohon, tergolong langka karena sifat biologi dan kondisi lingkungan tempat tumbuh. Ciri utama D. blumei yaitu dapat tumbuh hingga ketinggian $6 \mathrm{~m}$ dan pada pangkalnya diselimuti oleh rambut-rambut berwarna kemerahan mengkilat (Darma, Lestari, \& Priyadi, 2015). Literatur penelitian fenologi paku terutama D. blumei sangat terbatas. Penelitian ini bertujuan untuk mengetahui fase fenologi daun dan menganalisa korelasi tiap fase fenologi dengan faktor iklim (suhu dan curah hujan).

\section{METODOLOGI}

\section{A. Spesies Tanaman}

Paku pohon berkembang dengan memproduksi daun baru yang muncul dari pusat apikal batang, Daun yang tua lepas dan meninggalkan bekas tangkai daun pada batang (Blair et al., 2017).

Penelitian ini mengamati satu populasi D. blumei yang tumbuh secara alami dan ditanam di Kebun Raya "Eka Karya" Bali (Gambar 1). Populasi ini dipilih untuk memudahkan pengamatan fenologi daun. Kebun Raya "Eka Karya" Bali terletak di ketinggian $1.250 \mathrm{~m}$ di atas permukaan laut pada koordinat $8.26^{\circ}-8.28^{\circ}$ LU dan $115.15^{\circ}-115.16^{\circ} \mathrm{BT}$. 


\section{B. Variabel Fenologi}

Metode yang digunakan untuk menentukan fenologi daun pada paku pohon berdasarkan Lee et al. (2009a) bahwa 30 paku pohon dewasa dengan kriteria minimal memiliki satu tangkai daun. Fenologi daun meliputi munculnya daun, daun layu, daun dewasa, lepasnya spora diamati tiap akhir bulan dari bulan Mei 2015 sampai Mei 2016. Munculnya daun didefinisikan sebagai tahapan dalam pembentukan daun (daun menggulung). Setiap daun baru yang terbentuk diberi label menggunakan mikolin berwarna kuning. Daun yang berkembang di-definisikan sebagai tahapan ketika daun mulai berkembang namun berlum sampai pada tahapan pembentukan spora. Daun dewasa didefinisikan sebagai daun yang sudah berkembang sempurna ditandai dengan dibentuknya spora. Daun layu ditandai dengan perubahan warna daun menjadi hitam dan sudah mengering $90 \%$ dari total luas daun.

\section{Analisis Statistika}

Statistika deskriptif digunakan untuk menghitung berapa lama fase fenologi daun muncul hingga dewasa, spora masak, spora lepas dan daun layu. Korelasi Spearman digunakan untuk melihat korelasi antara faktor iklim dengan fenologi. Koefisien korelasi dihitung berdasarkan jumlah individu tiap tahapan fenologi (munculnya daun, daun berkembang, daun dewasa, spora masak dan spora lepas) tiap bulan dan faktor iklim (rata-rata suhu dan curah hujan bulanan). Data iklim diperoleh dari stasiun cuaca Kembang Merta yang terdekat dengan lokasi penelitian. Data suhu dan curah hujan dikumpulkan dari bulan Mei 2015 sampai Mei 2016.

\section{HASIL DAN PEMBAHASAN}

\section{A. Hasil}

\section{Munculnya daun}

Jumlah daun setiap fase mengalami penurunan dari munculnya daun hingga daun layu. Selama bulan Mei 2015 sampai
Mei 2016 sebanyak 157 daun baru muncul tetapi berkurang menjadi 116 daun yang berkembang, 72 daun dewasa dan 8 daun yang layu (Tabel 1). Daun muncul terutama pada bulan Mei hingga Agustus (Tabel 2). Tetapi munculnya daun tidak signifikan berkorelasi dengan suhu dan curah hujan (Tabel 3).

\section{Daun berkembang dan Daun Dewasa}

Rata-rata waktu yang dibutuhkan dari daun muncul hingga berkembang sempurna $46.76 \pm 3.9$ hari (Tabel 1). Sebagian besar daun berkembang sempurna mulai Mei hingga September (Tabel 2). Sebagian besar daun menghasilkan spora pada bulan Agustus dan September (Tabel 2). Daun berkembang memiliki korelasi negatif signifikan dengan suhu, namun tidak berkorelasi dengan curah hujan (Tabel 3).

\section{Daun layu}

Rata-rata waktu daun layu sebanyak $254,3 \pm 6,8$ hari (Tabel 1). Waktu daun layu terutama di bulan Februari (Tabel 2). Daun layu memiliki korelasi positif yang signifikan terhadap curah hujan (Tabel 3).

\section{Spora matang dan lepas}

Waktu yang diperlukan dari munculnya daun hingga menghasilkan spora matang sebanyak 50,40 \pm 4,0 hari (Tabel 1). Spora matang pada bulan Januari (Tabel 2). Waktu spora matang membutuhkan tidak berkorelasi dengan suhu dan curah hujan (Tabel 3). Sementara waktu ynag diperlukan spora matang hingga lepas memerlukan waktu 63,98 \pm 7,6 hari (Tabel 1). Spora yang lepas terutama terjadi pada bulan Mei (Tabel 2). Waktu spora lepas tidak berkorelasi dengan suhu dan curah hujan (Tabel 3).

\section{B. Pembahasan}

\section{Paku pohon}

Paku pohon seringkali dianggap sebagai tanaman evergreen yang tidak dipengaruhi oleh musim dan tanaman yang tumbuh lambat di hutan tropis. Meski 
demikian ada beberapa spesies yang memiliki fenologi daun musiman dan tingkat pertumbuhan yang berbeda pada musim yang berbeda (Mehltreter \& Garcíafranco, 2008). Daun paku yang memiliki dua bentuk (dimorphism) kadang dikombinasikan dengan durasi hidup daun fertil yang pendek, karakteristik musiman paku di tropis. Sementara paku monomorphic tidak dipengaruhi oleh musiman, sebagai konsekuensi daun yang tidak berubah bentuk (Mehltreter \& Palacios-Rios, 2003). Dicksonia blumei merupakan paku monomorphic yang menghasilkan daun steril dan daun fertil. Jumlah daun steril lebih sedikit dibanding daun fertil. Secara morfologi daun steril dan fertil memiliki bentuk yang sama, yang membedakan hanya pada ada tidaknya spora. Pada daun steril tidak ditemukan pembentukan spora setelah tanaman melewati masa berkembang daunnya. Daun steril dan fertil memiliki ukuran dan bentuk yang serupa. Daun fertil juga memiliki durasi hidup yang lebih panjang dibanding daun steril (Lee et al., 2009).

\section{Musiman}

Fase fenologi paku dipengaruhi oleh faktor ekstrinsik dan intrinsik. Tidak banyak infromasi mengenai pengaruh faktor intrinsik sementara faktor ekstrinsik sebagian besar berupa iklim (Mehltreter, 2008). Fenologi paku dilaporkan dari beragam daerah dengan iklim yang berbeda. Di Taiwan bagian utara, dimana tidak terdapat perbedaan musim kemarau yang jelas, daun yang muncul tidak berkorelasi dengan suhu dan curah hujan. Sementara tahapan fenologi yang lain seperti daun berkembang, daun layu, spora matang dan lepas memiliki korelasi positif yang signifikan dengan suhu ((Lee et al., 2009).

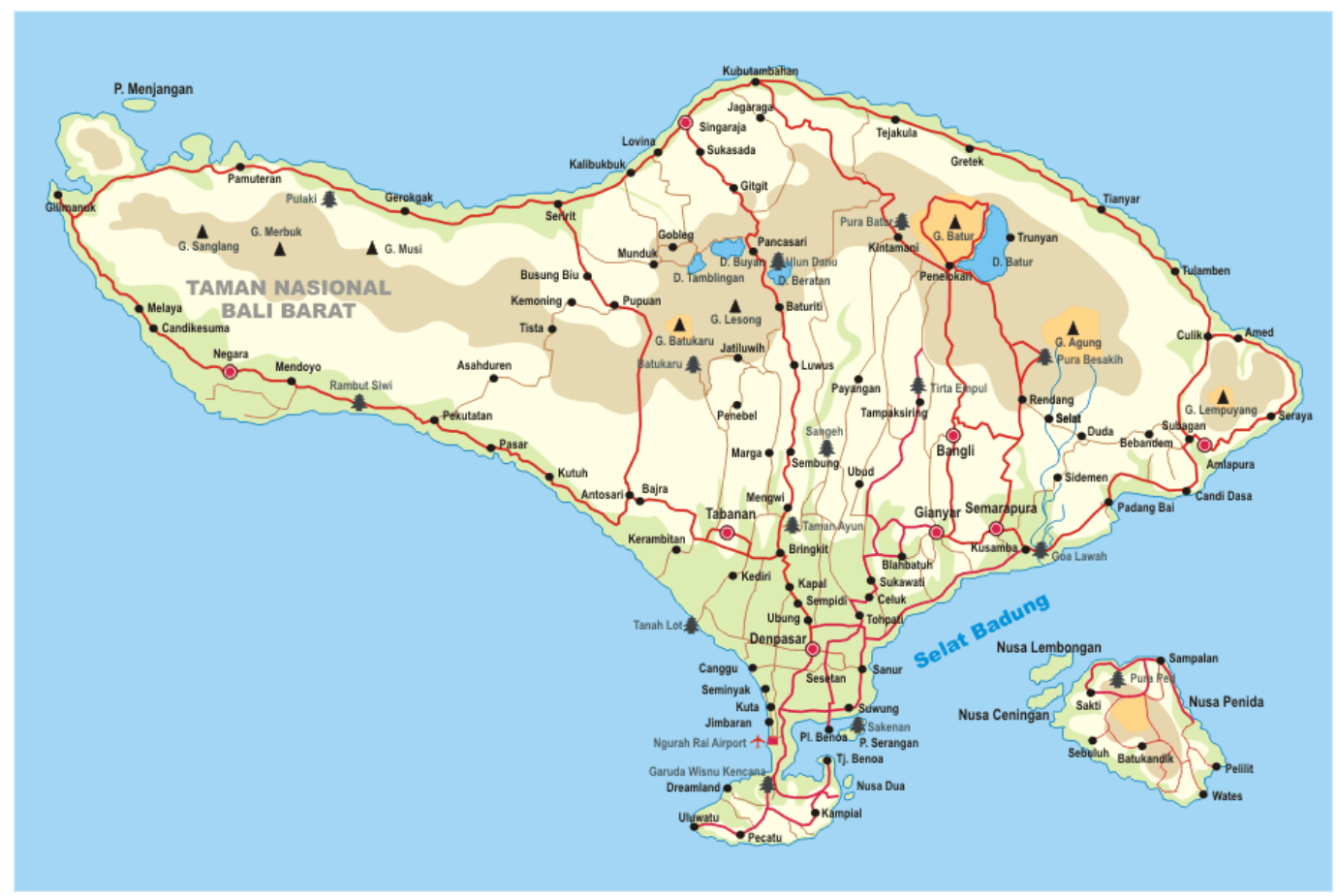

Gambar (Figure) 1. Peta lokasi penelitian ditunjukkan panah berwarna hijau (Map of the research location indicated by the green arrow) 


\section{Fenologi daun}

Jumlah daun yang berkembang lebih sedikit dibanding jumlah daun yang muncul, jumlah daun yang layu lebih sedikit dibanding jumlah daun yang berkembang (Tabel 1). Hasil ini sesuai dengan pengamatan fenologi Cyathea hancockii, Cyathea metteniana dan Cyathea podophylla (Lee et al., 2009). Suhu dan curah hujan tidak mempengaruhi jumlah daun yang muncul (Tabel 3). Hasil ini berbeda dengan munculnya daun Dryopterisaffinis spp di daerah mediterania juga dipengaruhi oleh suhu (Landi, Zoccola, Bacaro, \& Angiolini, 2014). Dalam penelitian ini fase daun yang berkembang dan daun yang layu memiliki korelasi dengan suhu atau curah hujan, suhu berpengaruh negatif terhadap perembangan daun. Perkembangan daun dipengaruhi oleh suhu udara yang rendah pada bulan Juli. Hasil ini berbeda dengan fase berkembangnya daun C. hancockii leaves, C. metteniana and C. podophylla yang bekorelasi positive dengan suhu. Perbedaan ini disebabkan perbedaan lokasi.

Tabel (Table) 1. Fenologi D. blumei di Kebun Raya "Eka Karya" Bali dari Mei 2015 sampai Mei 2016). (D. blumei phenology at Bali Botanic Garden from May 2015 to May 2016)

\begin{tabular}{|c|c|c|c|c|c|c|c|c|}
\hline \multirow{2}{*}{$\begin{array}{l}\text { Jumlah } \\
\text { sampel } \\
\text { (Number } \\
\text { of } \\
\text { samples) }\end{array}$} & \multicolumn{4}{|c|}{ Jumlah daun (Number of leaves) } & \multicolumn{4}{|c|}{ Jumlah hari (Number of days) } \\
\hline & $\begin{array}{l}\text { Muncul } \\
\text { (Emerge) }\end{array}$ & $\begin{array}{l}\text { Berkembang } \\
\text { (Developing) }\end{array}$ & $\begin{array}{c}\text { Dewasa } \\
\text { (Mature) }\end{array}$ & $\begin{array}{c}\text { Layu } \\
\text { (Whitered) }\end{array}$ & $\begin{array}{c}\text { Muncul } \\
\text { hingga } \\
\text { berkembang } \\
\text { (Emerge to } \\
\text { developing) }\end{array}$ & $\begin{array}{c}\text { muncul } \\
\text { hingga spora } \\
\text { matang } \\
\text { (Emerges } \\
\text { until the } \\
\text { spores } \\
\text { mature) }\end{array}$ & $\begin{array}{c}\text { spora } \\
\text { matang } \\
\text { hingga } \\
\text { lepas (The } \\
\text { spores } \\
\text { ripen off) }\end{array}$ & $\begin{array}{c}\text { muncul } \\
\text { hingga } \\
\text { layu } \\
\text { (Emerge } \\
\text { to } \\
\text { whitered) }\end{array}$ \\
\hline 30 & 157 & 116 & 72 & 8 & $46,76 \pm 3,9$ & $50,40 \pm 4,0$ & $\begin{array}{l}63,98 \pm \\
7,6\end{array}$ & $\begin{array}{l}254,3 \pm \\
6,8\end{array}$ \\
\hline
\end{tabular}

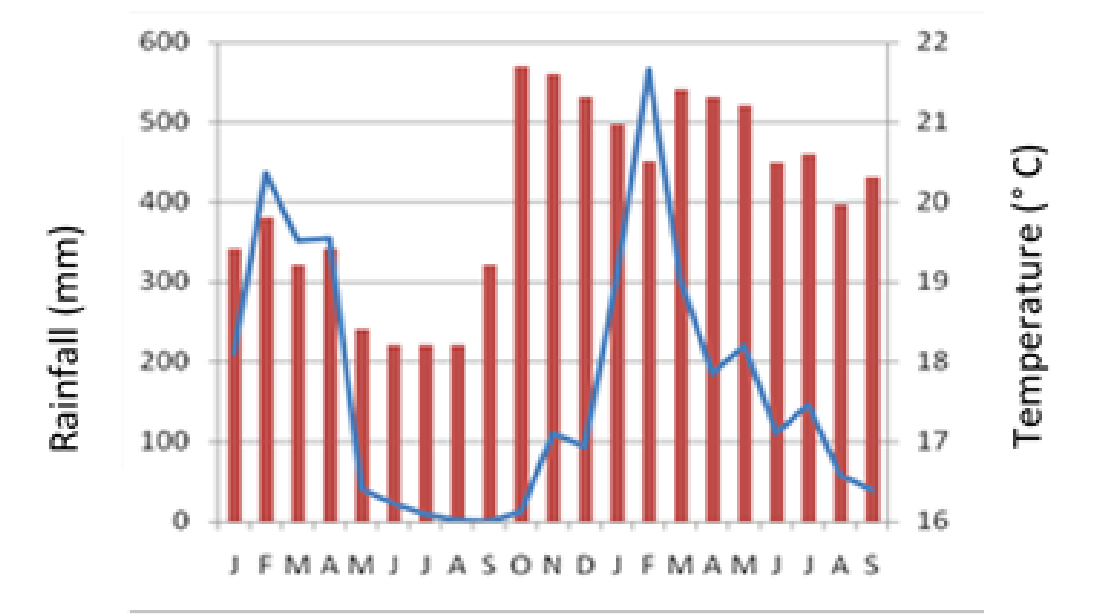

Gambar (Figure) 2. Grafik rata-rata temperatur (grafik batang) dan curah hujan (grafik garis) di lokasi penelitian dari January 2015 sampai September 2016) (Graph of Average temperature (bar) and Rainfall (line) at Research Sites from January 2015 to September 2016) 
Tabel (Table) 2. Jumlah daun D. blumei di setiap fase dari Mei 2015 sampai Mei 2016) (Number of leaves of $\underline{D}$. blumei in each phase from May 2015 to May 2016)

\begin{tabular}{|c|c|c|c|c|c|c|c|c|c|c|c|c|c|}
\hline Fase (Phase) & $\mathrm{J} 1$ & F2 & M3 & A4 & M5 & J6 & J7 & A8 & S9 & $\mathrm{O} 10$ & N11 & D12 & Total \\
\hline $\begin{array}{l}\text { Daun muncul } \\
\text { (Leaves } \\
\text { emerge) }\end{array}$ & 0 & 21 & 27 & 0 & 55 & 18 & 7 & 15 & 6 & 4 & 4 & 0 & 157 \\
\hline $\begin{array}{l}\text { Daun } \\
\text { berkembang } \\
\text { (Developing } \\
\text { leaves) }\end{array}$ & 3 & 9 & 15 & 0 & 21 & 17 & 24 & 14 & 9 & 1 & 2 & 0 & 115 \\
\hline $\begin{array}{l}\text { Daun dewasa } \\
\text { (Mature } \\
\text { leaves) }\end{array}$ & 3 & 6 & 2 & 0 & 5 & 0 & 5 & 27 & 13 & 8 & 3 & 0 & 72 \\
\hline $\begin{array}{l}\text { Daun layu } \\
\text { (Whitered } \\
\text { leaves) }\end{array}$ & 0 & 6 & 0 & 0 & 1 & 0 & 0 & 1 & 0 & 0 & 1 & 0 & 9 \\
\hline $\begin{array}{l}\text { Spora matang } \\
\text { (Mature } \\
\text { spores) }\end{array}$ & 34 & 5 & 0 & 0 & 0 & 0 & 0 & 0 & 0 & 0 & 16 & 0 & 55 \\
\hline $\begin{array}{l}\text { spora lepas } \\
\text { (Spores off) }\end{array}$ & 0 & 0 & 8 & 0 & 1 & 0 & 0 & 2 & 0 & 0 & 0 & 0 & 11 \\
\hline
\end{tabular}

Tabel (Table) 3. Korelasi antara fase fenologi D. blumei dengan temperatur bulanan dan curah hujan dari Mei 2015 sampai Mei 2016) (Correlation between the phenology phase of $\underline{D}$. blumei with the monthly temperature and precipitation from May 2015 to May 2016)

\begin{tabular}{|c|c|c|c|c|c|c|}
\hline & $\begin{array}{l}\text { Muncul } \\
\text { (Emerge) }\end{array}$ & $\begin{array}{l}\text { Berkembang } \\
\text { (Developing) }\end{array}$ & $\begin{array}{l}\text { Dewasa } \\
\text { (Mature) }\end{array}$ & $\begin{array}{l}\text { Layu } \\
\text { (Whitered) }\end{array}$ & $\begin{array}{l}\text { Spora matang } \\
\text { (Mature } \\
\text { Spores) }\end{array}$ & $\begin{array}{l}\text { Spora lepas } \\
\text { (Spores Off) }\end{array}$ \\
\hline $\begin{array}{l}\text { Suhu } \\
\text { (Temperature) }\end{array}$ & $-0,439^{\operatorname{tn}}$ & $-0,821^{* *}$ & $-0,435^{\text {tn }}$ & $0,017^{\text {tn }}$ & $0,330^{\text {tn }}$ & $0,134^{\text {tn }}$ \\
\hline $\begin{array}{l}\text { Curah hujan } \\
\text { (Rainfall) }\end{array}$ & $0,055^{\mathrm{tn}}$ & $-0,216^{\text {tn }}$ & $-0,291^{\text {tn }}$ & $0,702^{*}$ & $0,374^{\text {tn }}$ & $0,213^{\text {tn }}$ \\
\hline
\end{tabular}

Keterangan (Remarks): ** = Sangat nyata pada taraf 1\% (Very significant at level of $1 \%), *=$ Nyata pada taraf (Significant at level of $5 \%), \mathrm{tn}=$ Tidak nyata (No significant)

Daun layu merupakan respon komunikasi cepat antara ketersediaan dan kehilangan sumber daya dimana sinyal gula dan pengaturan hormon memainkan peran utama. Daun layu D. blumei memiliki korelasi positif dengan curah hujan, tapi hasil ini berbeda dengan kematian daun Dymochlaena truncatula di Brazil yang memiliki korelasi negatif dengan curah hujan (de Paiva Farias, de Paiva Farias, Erickson Nascimento da Costa, Abraão
Araújo da Silva, \& Barros, 2015). Tetapi daun layu pada sebagian besar paku tidak signifikan dipengaruhi oleh curah hujan namun suhu (Lee et al., 2018). Meski demikian penelitian kematian daun A. firma dipengaruhi oleh suhu dan curah hujan yang meningkat. Hal ini menunjukkan bahwa ketersediaan air bukanlah merupakan faktor pembatas yang menyebabkan kematian daun. Suhu yang tinggi selama penghujan dapat menyebab- 
kan stress air pada paku pohon (Mehltreter, 2008). Selama musim penghujan, D. blumei harus beradaptasi dengan jumlah air yang besar yang membuat tanah menjadi jenuh. Untuk mengurangi evapotranspirasi, tanaman ini meng-gugurkan daunnya untuk mengurangi jumlah penguapan.

\section{Spora matang dan spora lepas}

Pematangan/pelepasan spora adalah entri penting dari perkecambahan spora berikutnya dan reproduksi pakis yang sukses. Pelepasan spora dipengaruhi oleh suhu atau curah hujan (Lee et al., 2018). Pada paku monomorphic, daun fertil memiliki dua fungsi sebagai alat reproduksi dan fotosintesis (Lee et al., 2009). Warna sporangium digunakan untuk mengetahui kematangan spora. Sporangium D. blumei yang sudah matang memiliki warna coklat. Sporangium yang terbuka menjadi tanda bahwa spora telah lepas. Suhu dan curah hujan tdak berpengaruh terhadap kematangan spora dan pelepasan spora D. blumei. Hal ini berbeda dengan pernyataan (Lee et al., 2018). Perbedaan ini disebabkan perbedaan lokasi sehingga mempengaruhi iklim setempat.

\section{KESIMPULAN DAN SARAN}

\section{A. Kesimpulan}

Rata-rata jumlah hari yang diperlukan dari munculnya daun hingga layu adalah 254,31 $\pm 6,8$ hari. Meski fase daun layu berkorelasi positif dengan curah hujan, namun fase kesuburan daun dan produksi daun tidak berkorelasi dengan faktor iklim atau variasi musiman. Hasil ini memperlihatkan bahwa fenologi daun D. blumei tidak dipengaruhi oleh variasi musiman.

\section{B. Saran}

Untuk menarik kesimpulan fenologis yang lebih umum, perlu dilakukan studi fenologis jangka panjang di lokasi berbeda di iklim tropis.

\section{UCAPAN TERIMA KASIH}

Penulis ingin mengucapkan terima kasih kepada Moh Adenan yang sudah membantu mengumpulkan data di lapangan dan Kepala Kebun Raya "Ekaa Karya" Bali atas kesempatan untuk melakukan penelitian ini.

\section{DAFTAR PUSTAKA}

Blair, D.P., Blanchard, W., Banks, S.C., \& Lindenmayer, D.B. (2017). Nonlinear growth in tree ferns, Dicksonia antarctica and Cyathea australis. PLoS ONE, 12(5), 1-15. https:// doi.org/10.1371/journal.pone.017690 8

Chiu, T. (2013). 碩士論文 Phenological Patterns of Three Cyathea Tree Ferns in Northeastern Taiwan 邱子芸.

Darma, I.D.P., Lestari, W.S., \& Priyadi, A. (2015). Habitat alami tumbuhan paku kidang (Dicksonia blumei (Kunze) Moore) di Kawasan Hutan Bukit Tapak Pulau Bali. Buletin Kebun Raya, 18(1), 4-7.

de Paiva Farias, R., Erickson Nascimento da Costa, L., Abraão Araújo da Silva, I., \& Barros, I.C.L. (2015). Phenological studies of selected leaf and plant traits of Didymochlaena truncatula (Dryopteridaceae) in a Brazilian submontane tropical rainforest. Nordic Journal of Botany, 33(2), 249-255. https://doi.org/ 10.1111/njb.00656.

Landi, M., Zoccola, A., Bacaro, G., \& Angiolini, C. (2014). Phenology of Dryopteris affinis ssp. affinis and Polystichum aculeatum: Modeling relationships to the climatic variables in a Mediterranean area. Plant Species Biology, 29(2), 129-137. https:// doi.org/10.1111/1442-1984.12000.

Lee, P.H., Chiou, W.L., \& Huang, Y.M. (2009). Phenology of three Cyathea (Cyatheaceae) ferns in northern Taiwan. Taiwan Journal of Forest Science, 24(4), 233-242. 
Lee, P.H., Huang, Y.M., \& Chiou, W.L. (2018). Fern phenology. In Current Advances in Fern Research. https://doi.org/10.1007/978-3-31975103-0_18.

Lee, P.H., Lin, T.T., \& Chiou, W.L. (2009). Phenology of 16 species of ferns in a subtropical forest of northeastern Taiwan. Journal of Plant Research, 122(1), 61-67. https://doi.org/10.1007/ s10265-0080191-7.

Mehltreter, K. (2008). Phenology and habitat specificity of tropical ferns. Biology and Evolution of Ferns and Lycophytes, 201-221. https://doi.org/ 10.1017/CBO9780511541827.009.

Mehltreter, K., \& García-franco, J.G. (2008). American Fern Society Leaf Phenology and Trunk Growth of the Deciduous Tree Fern Alsophila firma (Baker) D.S. and Trunk Leaf Phenology Tree Fern Alsophila firma Lower Mexican of the Deciduous. American Fern Journal, 98(1), 1-13.

Mehltreter, K., \& Palacios-Rios, M. (2003). Phenological studies of Acrostichum danaeifolium (Pteridaceae, Pterido- phyta) at a mangrove site on the Gulf of Mexico. Journal of Tropical Ecology, 19(2), 155-162. https:// doi.org/10.1017/S0266467403003171

Mehltreter, K., \& Sharpe, J.M. (2013). Causes and consequences of the variability of leaf lifespan of ferns. Fern Gazette, 19(6), 192-204. https:// doi.org/10.1021/jp908090s

Noland, K., Norman, E., Peterson, C.L., \& Richardson, M.L. (2017). Extrinsic factors influence phenology of the epiphytic hand fern (Cheiroglossa palmata). Botany, 895, 1-21. https://doi.org/10.1152/japplphysiol.0 0745.2016.

Quintanilla, L.G., \& Pías, B. (2018). Convergence in leaf phenology traits of two understorey ferns in the northwestern Iberian Peninsula. Journal of Plant Ecology, 11(1), 92102. https://doi.org/10.1093/jpe/ rtw125.

Thomas, H. (2013). Senescence, ageing and death of the whole plant. New Phytologist, 197(3), 696-711. https:// doi.org/10.1111/nph.12047. 